\title{
Energy Efficiency and Policy Analysis for Household in DI Yogyakarta (Yogyakarta Special Region) Indonesia
}

\author{
Tony K. Hariadi ${ }^{\#}$, P.Jutta Prahara ${ }^{\#}$, Surya B. Lesmana ${ }^{*}$, Raouf Saidi ${ }^{1}$ \\ \# Department of Electrical Engineering, Universitas Muhhamadiyah Yogyakarta, Yogyakarta, Indonesia \\ E-mail: tonykhariadi@umy.ac.id \\ * Department of Civil Engineering, Universitas Muhhamadiyah Yogyakarta, Yogyakarta, Indonesia \\ E-mail: monolesmana@umy.ac.id
}

${ }^{1}$ Energy Research Center of the NetherlandsWesterduinweg 3, 1755 LE Petten, P.O. Box 1, 1755 ZG Petten, The Netherlands

E-mail: said@ecn.nl

\begin{abstract}
Energy demands has been increasing from time to time, while there is energy supply decreasing in the last three decades. This has given a big impact in the energy price. Related to this problem, the common policies on the energy consumption sector are increase energy supply, or reduce energy consumption. This project was aimed to simulate energy efficiency action plan and analyse the impact on energy efficiency in household by reducing energy consumption. A survey to collecting data on common devices used in household has been done, i.e. information about price and energy consumption of the devices. There are two ways to doing this energy efficiency: changing the energy intensive equipment to more energy- efficient equipment, and changing the consumer behaviour. Household will only attract to apply energy efficiency scenarios on several conditions: low initial investment, short payback period of that investment, and high total energy and cost savings. We can applying several energy efficiency scenarios, and simulate the saving of the government (spending fewer subsidies) and also the saving from household (spending less energy loss, and payback period). The analysis demonstrated that replacing old appliances with newer technology would decrease energy consumption, but also increase the household spending for investment on new appliances. We also simulated further payback period with and without subsidy. The use of accurate energy performance measurement standards and protocols is the base of effective implementation of energy efficiency policies for appliances and equipment. This standards and protocols should be provided in place and updated regularly.
\end{abstract}

Keywords - Energy efficiency; energy policy; energy consumption for household

\section{INTRODUCTION}

The world is facing a crisis triggered by imbalanced energy demand and supply, and before it transform into global crisis we have to take an immediate measure. Until 2003, the energy consumption of the world have been growing rapidly at the average of $1.5 \%$ per year. Oil consumption has rocketed from 6630 million tons of oil equivalents (Mtoe) to 11,163 Mtoe from 1980 to 2009 [1]. Global energy demand grows by $40 \%$ between 2009 and 2025 with oil remain the leading fuel, although natural gas demand also rises significantly [2].

Indonesia is facing the same problem, as the demand for power is growing in the country, and production would also need to increase to meet the demand [3]. Indonesia is shifting slowly from oil exporter to oil importer due to this problem. Presidential Decree No.5 of 2006 on National
Energy Policy and its Blueprint of National Energy Management 2005 - 2025 has been taken as a direct measure, along with The Energy Law No.30 of 2007 for the establishment of The National Energy Council (DEN) in national energy policy making. This Law also mandates implementation of specific energy conservation measures that are elucidated in the Law's explanatory Government Regulation No. 70 of 2009 [4]. Energy policy is very important, the national domestic and foreign policies are directly affected by the issues surrounding the reliability and security of energy supplies. The regional energy plan must referring to the national energy plan as mandated in the Local Government Act. The policies, strategies, and programs adopted by both the public and private sectors will directly impact the community [5].

There are two main factors of the household energy consumption increasing: the growing number of dwelling 
and the growing number on one person households is some country, and the growing comfort due to increase in the number of house appliances and a move to the larger house. The electricity intensity is clearly increasing in most countries, due to a growing number of new appliances such as IT devices as well as the spread of air conditioner [6].

\section{METHOD}

Residential energy users are interest in having a cheaper energy cost and may be interest in "social savings" in the term of $\mathrm{CO} 2$ emission reductions and global warming. Both can be achieved by adopting The Demand Side Management strategies that control actions on the per-house load. There should be an energy/load manager in each house take cares of levelling power consumptions below a certain threshold (minimizing the in-house power losses, shifting the activation of appliances in period, etc.) [7]. This is related with building retrofits, which are the important activities in the construction industry. One of those many activities is the reduction of energy consumption (energy retrofit) [8].

This project was done to evaluate different policy scenario for electrical energy in household in Daerah Istimewa Yogyakarta, and the objective was to simulate energy efficiency action plan and analyse the impact on energy efficiency in household by reducing electrical energy consumption. And furthermore to: Utilize the energy efficiently and rationally without reducing the energy really needed in the national development; Using the energy optimally as needed so that will reduce the cost incurred (cost effective energy saving); Maintaining the sustainability of natural resources in the form of an energy source, and to realize a sustainable energy supply capabilities. This can be done through a policy of tecnology selection, and use the energy efficiently and rationally.

However, on average, energy users would not change their appliance use. The adoption of more efficient appliances is not more likely in Indonesian household, including in Yogyakarta. But indeed, the awareness rate of energy consumed and energy efficiency of all appliances exept air conditioner is significantly higher in Yogyakarta. If the electricity price increased by $10 \%$, consumers will significantly more likely to reduce their electrical appliances use [9].

A random survey was done in households with different installed electricity rating, to collect data on the usage of electrical devices. Data collection then grouped into key data: The most common used electrical devices; Investment cost; Energy consumption; Electricity rating in the household.

The electricity consumer in Yogyakarta was the household sector (54.94\%), business/industries (33.38\%), and social/government agencies (11.68\%) [10], while the electronic devices were dominated by air conditioner (AC), refrigerator, television, and desktop personal computer (PC).

Data analysis was done using several energy efficiency scenario, and assumption for data analysis were determined based on the survey result. Energy efficiency can be done in two ways, by changing technology (from energy-intensive to more energy-efficient equipment's) and changing consumer behaviour, which are require an initial investment. From an economist perspective, this energy efficiency choice fundamentally involve investment decisions that trade off higher initial cost and uncertain lower future energy operating cost [11]. For every energy user, the interest to invest in an energy efficiency measure depend on: The size of the initial investment; The payback period of that investment; The total energy and cost savings.

TABLE I

SURVEY RESULT

\begin{tabular}{|c|c|c|}
\hline $\begin{array}{l}\text { Electricity } \\
\text { Price }\end{array}$ & $\begin{array}{l}\text { Basic Electricity } \\
\text { Tariff (TDL) } \\
2010\end{array}$ & $\begin{array}{ll}\bullet & \mathrm{R}-1 / \mathrm{TR} 450-900 \mathrm{VA} \\
& \text { at IDR } 495 / \mathrm{kWh} \\
\text { - } & \mathrm{R}-1 / \mathrm{TR} 1300-2200 \\
& \mathrm{VA} \text { at IDR } 790 / \mathrm{kWh}\end{array}$ \\
\hline \multicolumn{3}{|c|}{$\begin{array}{l}\text { Most of housing with installed capacity more than } 3500 \mathrm{VA} \text {, } \\
\text { has implemented energy efficiency scenario, therefore were not } \\
\text { put into calculation, however their behavioural data were } \\
\text { collected to support }\end{array}$} \\
\hline Survey Data & $\begin{array}{l}\text { Respondent } \\
\text { - Urban: } 320 \\
\text { - Suburban: } \\
120\end{array}$ & \begin{tabular}{ll}
\multicolumn{2}{l}{ Ownership } \\
- & Refrigerator: $66 \%$ \\
- & CRT TV: $55 \%$ \\
- & Air Conditioner: $29 \%$ \\
\end{tabular} \\
\hline
\end{tabular}

\section{RESULT}

\section{A. Refrigerators}

A refrigerator operated approximately 16 hours in $\mathrm{ON}$ mode and 8 hours in toggle mode. Policy scenario: replacement with energy saving refrigerator. Energy efficiency used these assumption:

- Current type of refrigerator : $0.120 \mathrm{~kW}$ and replaced with $0.07 \mathrm{~kW}$ IDR O/fridge

- Operation time : 16 hours/day

- New type of refrigerator : energy consumption $0.03 \mathrm{~kW}$

- Price IDR 1,500,000

- Generating costs : IDR 1,300 at normal time and

- IDR 1,500 at peak time (5pm to $10 \mathrm{pm})$

From the calculation, the electrical energy cost savings and domestic customers for the replacement of refrigerator are: NVP Difference for $0.12 \mathrm{~kW}$ and $0.07 \mathrm{~kW}$ refrigerators with the price of IDR 495 and IDR 790. The return of investment of IDR 1,053 after 44 months can only be achieved by a household with a $0.12 \mathrm{~kW}$ refrigerator at an energy cost of IDR 790. Without NVP savings, a household with a $0.12 \mathrm{~kW}$ at energy cost of IDR 495 is the next potential customer. And for the NVP savings calculations, the groups with a $0.07 \mathrm{~kW}$ were not potential. This indicated in Figure 1.

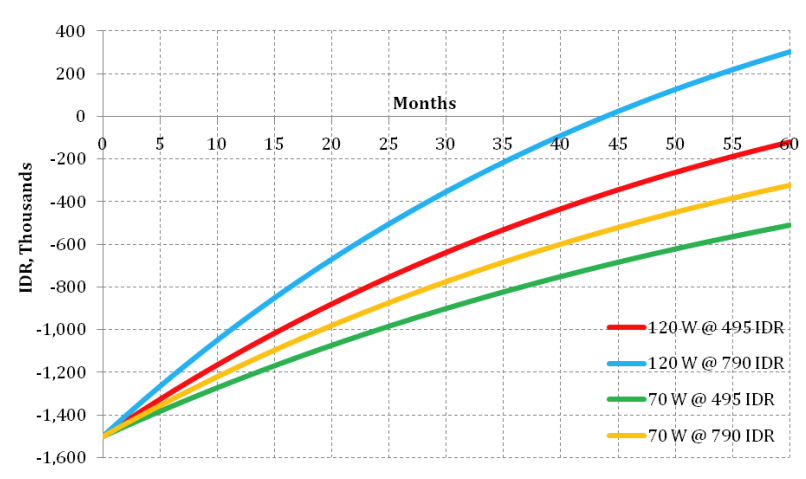

Fig.1 NVP Difference for $0.12 \mathrm{~kW} 0.07 \mathrm{~kW}$ refrigerator with price IDR 495 and IDR 790 
Energy saving potential is shown in figure 2:

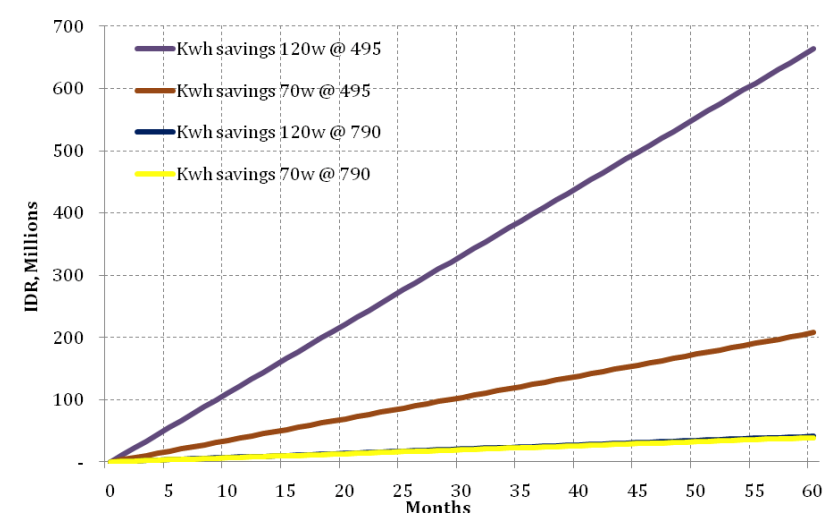

Fig.2 Energy Saving Potential

Barrier Analysis : Financial barriers: the upfront investment cost of 1.5 million is probably too high and the payback period is too long to offer the household any financial benefits. Social barriers, knowledge about EE refrigeration can be used for consumer who are already thinking about buying a new refrigerator (labelled refrigerator).

Policy Measures : Increasing the electricity price by $20 \%$ reduces the payback period from 44 months to 36 months for the 790 group with $0.12 \mathrm{~kW}$. The barrier for the 495 group with $0.07 \mathrm{~kW}$ is the same as the 495 group with $0.12 \mathrm{~kW}$ which is the upfront investment cost and does not offer the household financial benefits.

From a household perspective the IDR 495 group the following scenarios are possible:

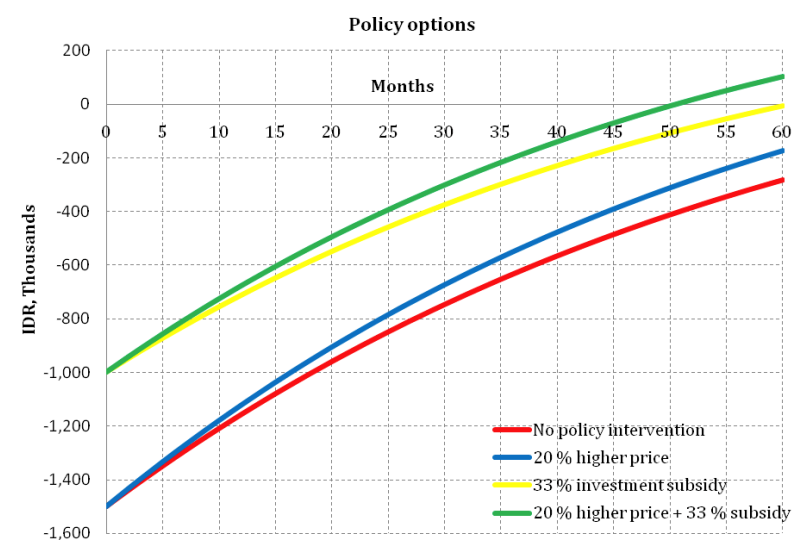

Fig.3 Policy option for a weighted average of $0.12 \mathrm{~kW}$ and $0.07 \mathrm{~kW}$ refrigerators in the 495 group

The electricity cost is still too low to make a large impact on total savings after 5 years, and the only real benefit is the reduced investment cost. From this we can conclude: Only the option with a subsidy break even; Only the option with a subsidy and a higher energy price will generate savings for the household.

This demands a different approach: we only analyse consumers in the market for a new refrigerator instead looking at the consumers changing their refrigerator immediately. Here they have a choice between a $75 \mathrm{w}$ unit at
1.75 million IDR and more efficient $30 \mathrm{w}$ unit at 1.5 million IDR.

The financial conditions are far more favourable, there is no financial barrier exist. The remaining barrier is related to why consumers would choose for more efficient option, due to a lack of knowledge about an Energy Efficient refrigerator.

Therefore, residential energy efficiency project should be treated as a financial investment. The attractiveness of it depends on the return expected by the owner or investor. It is important to be aware that the efficiency of equipment may decrease over time due to a normal use, and replacement of technology often implies an increase in efficiency. And inflation is a familiar concept of money value change over time. It is must be well understood that most things bought or must service received today will cost more in the future because of the inflation [12].

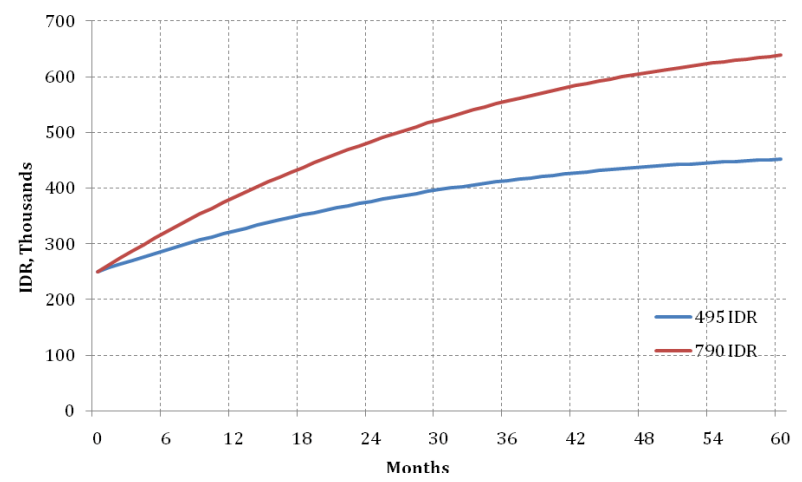

Fig.4 NVP Difference for new refrigerator consumers at price IDR 495 and IDR 790

\section{B. Television}

Energy efficiency of the television use is difficult as it related to consumers behaviour. The normal use of television on average is 10 hours a day. It can be reduced to 8 hours, and put it off.

TABLE II

ASSUMPTION CONDITIONS OF REDUCED OPERATING TIME OF TELEVISION

\begin{tabular}{|l|l|}
\hline $\begin{array}{l}\text { Normal operating time: } \\
10 \text { hours }\end{array}$ & 29 inch television use $0.15 \mathrm{~kW}$ \\
\hline $\begin{array}{l}\text { Reduce operating time: } \\
2 \text { hours }\end{array}$ & $\begin{array}{l}21 \text { inch television in standby } \\
\text { mode use } 0.005 \mathrm{~kW}\end{array}$ \\
\hline $\begin{array}{l}21 \text { inch television use } \\
0.1 \mathrm{~kW}\end{array}$ & $\begin{array}{l}29 \text { inch television in standby } \\
\text { mode use } 0.0075 \mathrm{~kW}\end{array}$ \\
\hline $\begin{array}{l}\text { Generating costs : IDR } 1,300 \text { at normal time and IDR } 1,500 \\
\text { at peak time }(5 \mathrm{pm} \text { to } 10 \mathrm{pm})\end{array}$ \\
\hline
\end{tabular}

Barrier analysis : The main barrier is habit and lack knowledge about energy conservation. Reduce the operating time for two hours from 10 become 8 hours in a day, (and if possible is operating only on peak hour between $5 \mathrm{pm}$ to 10 $\mathrm{pm}$ ), is hard to be done. Also, the use of stand-by mode for much easier access with remote control instead of turn off the television completely also consumes energy.

Policy Measures and Recommendation : The attitude of general public is an important aspect of energy efficiency policy framework. Awareness is the first step to create positive attitude towards energy efficiency; the awareness of environmental problems, climate change, or other drivers 
behind energy efficiency. Measures to creates awareness are promotion campaigns, creation of access points of information, and education on energy efficiency.

Awareness and attitude play a role in two stages - the benefits of energy efficiency and the instrument used to promote this. The voluntary approaches also can be done for successful campaign. Introducing efficient electricity is available to customers on a voluntary basis. Efficient electricity pricing is a voluntary market initiative of the electricity sector.

\section{Air Conditioner $(A C)$}

AC is secondary or tertiary needs in household, only $29 \%$ of total household consumers. But considering AC's are include in high energy capacity for household, the calculation should be done to give perspective of quite high energy savings potential. Scenario: replace an old AC with energy efficient one (with inverter).

TABLE III

ASSUMPTION OF AIR CONDITIONER REPLACEMENT

\begin{tabular}{|c|c|}
\hline $\begin{array}{c}\text { Old type of AC's : } 0.7 \\
\text { kW IDR 0/AC's }\end{array}$ & Operation time : 8 hours/day \\
\hline New type of AC's : & Generating costs: IDR 1,300 \\
$0.175 \mathrm{~kW}$ Price IDR & at normal time and IDR 1,500 \\
$5,000,000$ & at peak time (5 pm to $10 \mathrm{pm})$ \\
\hline
\end{tabular}

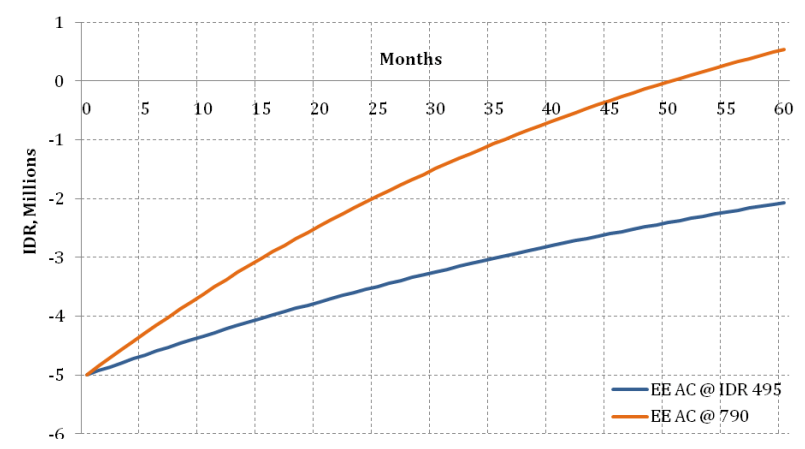

Fig.5 NVP Difference for $0.7 \mathrm{~kW}$ AC's replacement with price IDR 495 and IDR 790

Only the household at case 2 will return their investment of IDR 46,079 after 51 month, while at case 1 household will return their investment after 10 years. Also the customers are quite low, hence we will only analyse the 790 IDR group as the 495 group normally cannot afford an AC.

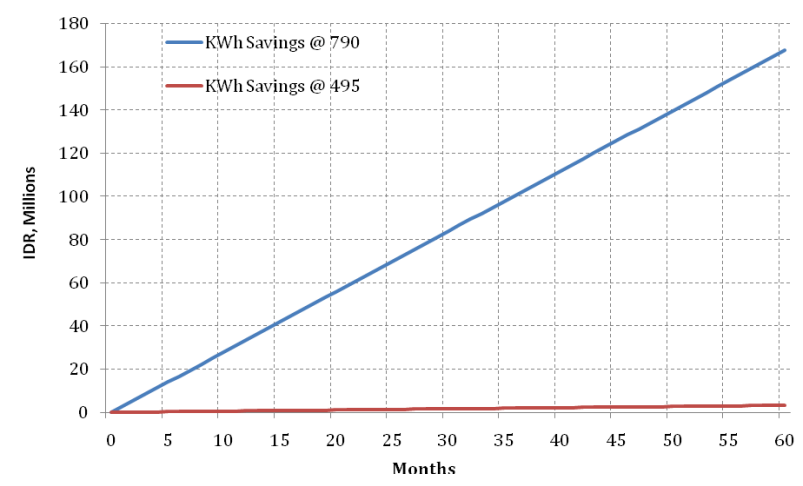

Fig.6 Energy Savings for $0.7 \mathrm{~kW}$ AC's replacement with price IDR 495 and IDR 790
The total technical potential saving is for case 2 (case 1 does not significant savings), though this savings does not quite high. Total energy savings are identified around 167.5 GWh within five years, or simply $33.5 \mathrm{GWh}$ in one year $(1 \%$ from total energy consumption in 2010 with assumption growth $6.75 \%$ per year and the base year is 2008).

Barrier Analysis: Financial barrier: the upfront investment cost of 5 million is probably too high and the payback period is too long to offer the household any financial benefits. Policy barrier, no energy labeeling and no policy for both inefficient and efficient products. Only one brand has issued such equipment's. Social barrier, knowledge about EE air conditioner can be used for consumer who are already thinking about buying a new air conditioner (labelled AC).

Policy Measures : From household perspective for price IDR 790 these scenarios are possible:

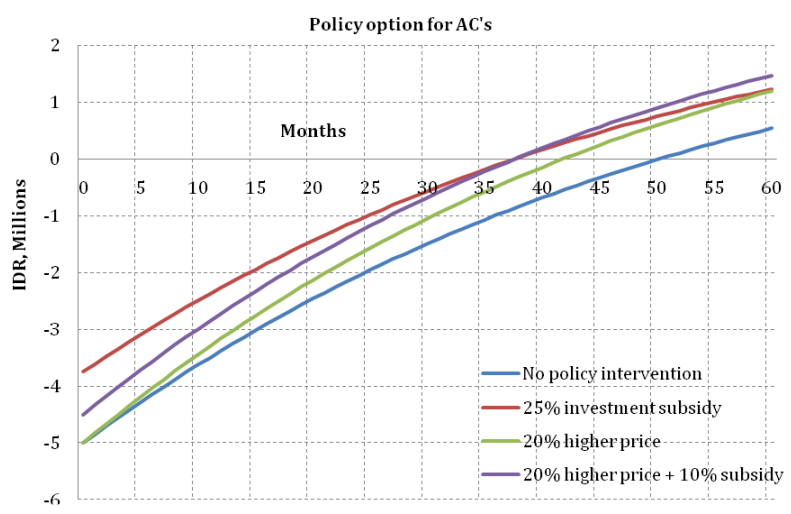

Fig.7 Policy options for $0.7 \mathrm{~kW}$ AC's replacement at price IDR 790

The electricity cost give an impact on total saving after 5 years (all scenarios break-even). But two scenarios, with no policy intervention and $20 \%$ higher energy price, did not give much benefit that are break even on 51 and 42 months. Not attractive yet, considering the investment is for secondary needs purpose only. From this we can conclude: Only the option with a subsidy is attractive for investment. The option with a subsidy and a higher energy price with subsidy will give attractive option for household.

This need a different approach: we only analyse consumers in the market for a new AC, instead of looking at consumers changing their AC immediately. Here they have a choice between a $700 \mathrm{w}$ unit at 3 million IDR and more efficient $175 \mathrm{w}$ unit at 5 million IDR. Below is the NVP analysis for this situation:

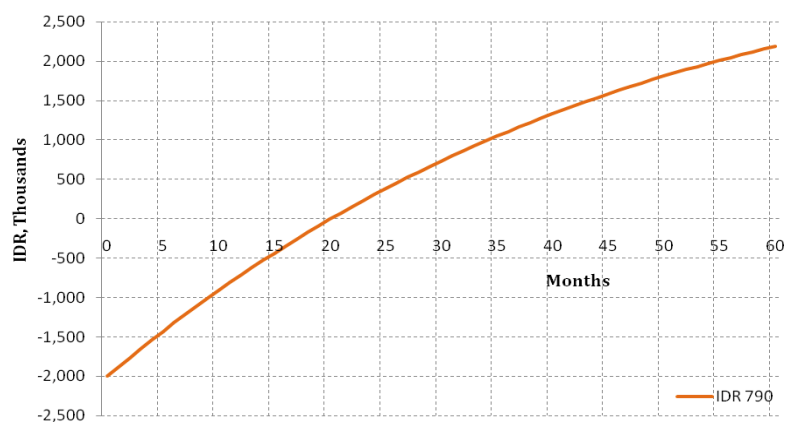

Fig.8 NPV Difference for New Air Conditioning Consumers at price IDR 790 
The financial conditions are far more favourable even though the financial barrier still exist (the difference in investment cost). The other barrier is related to why consumers would choose for more efficient option, due to a lack of information about an Energy Efficient air conditioner (AC).

\section{CONCLUSIONS}

Mechanism of the policy with recommendation : The use of accurate energy performance measurement standards and protocols is the base of effective implementation for appliances and equipments. This standards and protocols have to be provided in place and updated regularly. Household should replace older appliances, i. e. refrigerator, television, and air conditioner, with the efficient ones, and make sure that they are not added to the total market. Manufacturer and store could participate to introduce recycling scheme, and the government involvement ensure this schemes work. Limiting appliances conditions for 5 or for maximum 8 years depend on the manufacturer specification. Labelling or standardization, through product labels at the level of sales that contain information about energy efficiency for energy saving. Manufacturer involvement. The scheme could share the subsidy since they will benefit from labeling and 5 years of warranty. Ensure adequate resources allocated to maintaining the stringency of energy efficiency requirements for appliances. Ensure appropriate policies to encourage manufacturer to deliver an energy efficient product.

Subsidy is not recommended because it is difficult to imply without any distortion (it has greater impacts than positive ones). Subsidy can be measured with: Investment cost: the full investment cost is to high but, 50\% invesment cost could solves the problem. However, there are also negative effects such as market distortion. Producers and retailers will tend to keep the price high and benefit from the subsidy. Payback period: higher energy costs are neccessary to promote energy efficiency behavior. Consumer will choose appliances with energy efficient technology. Increase the electricity gradually and structured would reduce subsidy that could be allocated for more important another development.

\section{ACKNOWLEDGMENT}

This research was done as part of Capacity Development and Strengthening for Energy Policy Formulation and Implementation of Sustainable Energy Projects in Indonesia (CASINDO).

\section{REFERENCES}

[1] M.H. Hasana,*, T.M.I. Mahliaa,b, Hadi Nurc, A Review on Energy Scenario and Sustainable Energy in Indonesia

[2] IEA World Energy Outlook 2011

[3] Sneha Shaharare1,2, T. Harinarayana1*, "Energy Efficient Air Conditioning System Using Geothermal Cooling - Solar Heating in Gujarat India”, Journal of Power Energy Engineering,vol.4, pp. 5771, 2014

[4] Peer Review on Energy Efficiency in Indonesia, Report Endorsed by the APEC Energy Working Group, 2012

[5] Cetak Biru Pengelolaan Energi Nasional 2006-2025 Sesuai Peraturan Presiden Nomor 5 Tahun 2006

[6] Energy Efficiency Trends and Policy in The Household and Tertiary Sectors, An Analysis Based on the ODYSSEE and MURE Databases, June 2015

[7] Rosario Miceli, "Energy Management and Snart Grids", Energies 2013, vol. 6, pp. 2262-2290, 2013

[8] Nikos Sakkas, Evangelos Kaltsis, "A Methodology for Introducing M\&V Adjustment during an Energy Retrofit Impact Assessment”, Open Journal of Energy Efficiency, vol.3, pp.77-84, 2014

[9] Muhammad Ery Wijaya, Tetsuo Tezuka, "Policy Making for Household Appliances Related Electricity Consumption in Indonesia - A Multictural Country”, Open Journal of Energy Efficiency, vol.2, pp.53-64, 2013

[10] Statistik Ketenagalistrikan dan Energi Tahun 2009, Direktorat Jendral Listrik dan Pemanfaatan Energi Departemen Energi dan Sumber Daya Mineral, 2009

[11] Kenneth Gillingham, Richard G. Newell, and Karen Palmer, "Energy Efficiency and Policy", in Discussion Paper, April 2009, RFF DP, pp. 9-13

[12] Nelson Fumo, Roy Crawford, “A Homeowner-Based Methodology for Economic Analysis of Energy Efficiency Measures in Residences", Open Journal of Energy Efficiency, vol.2, pp.97-106, 2013 